\title{
PENGARUH PENGENAAN PAJAK PENGHASILAN PASAL 22 DAN PAJAK PERTAMBAHAN NILAI BERDASARKAN UNDANG-UNDANG PERPAJAKAN GUNA MENENTUKAN PAJAK TERUTANG
}

\author{
Khasanah Sahara \\ Dwi Ratna Utari \\ Universitas Islam Kadiri Kediri \\ E-mail: khasanahsahara1 @ gmail.com
}

\begin{abstract}
Abstrak
Perusahaan Tenun Ikat Medali Mas merupakan perusahaan yang tidak memiliki Angka Pengenal Impor atau yang biasa disebut dengan API. Berhubung tidak memiliki Angka Pengenal Impor (API), maka meminta bantuan pihak lain untuk menjadi pelaksanaa impor bahan dari perusahaan tersebut. Perusahaan Tenun Ikat Medali Mas selain terkena Pajak Penghasilan (PPh) Pasal 22 dan Pajak Pertambahan Nilai (PPN), Perusahaan Tenun Ikat Medali Mas juga akan menanggung fee karena mengimpor melalui pihak lain dalam tahun berjalan yang harus di bayar oleh Wajib Pajak yaitu Pajak Penghasilan (PPh). Tujuan penelitian ini untuk mengetahui pengaruh pengenaan PPh Pasal 22 dan PPN berdasarkan UndangUndang Perpajakan guna menentukan Pajak Terutang.

Sumber data yang digunakan dalam penelitian ini adalah data primer dan data sekunder. Jenis data yang digunakan adalah data kualitatif dan data kuantitatif. Teknik pengumpulan data yang digunakan dalam penelitian ini adalah wawancara dan dokumentasi. Variabel dalam penelitian ini adalah PPh Pasal 22, PPN, pajak terutang. Jenis penelitian yang digunakan dalam penelitian ini adalah deskriptif kuantitatif yaitu dengan mendeskripsikan hasil nilai hitung dari data yang diperoleh.

Hasil penelitian ini menunjukkan jika Perusahaan Tenun Ikat Medali Mas melakukan impor sendiri tidak perlu membayarkan headling fee, tetapi jika melakukan impor dengan API pihak lain Perusahaan terkena PPh Pasal 22 dan PPN dalam menentukan Pajak Terutang dan masih terkena headling fee. Perusahaan menggunakan API sendiri maka PPh Pasal 22, PPN, dan Pajak Terutangnya lebih kecil, dibanding perusahaan menggunakan API perusahaan lain sehingga PPh Pasal 22, PPN dan Pajak Terutangnya lebih besar.
\end{abstract}


Berdasarkan uairan diatas Perusahaan Tenun Ikat Medali Mas sebaiknya melakukan impor dengan menggunakan API sendiri, karena jika memiliki API sendiri, Perusahaan Tenun Ikat Medali Mas tidak perlu mengeluarkan dana untuk headling fee, PPh Pasal 22, Pajak Pertambahan Nilai, dan Pajak Terutang dari perusahaan lebih sedikit daripada menggunakan API perusahaan lain.

\title{
Kata Kunci: PPh Pasal 22, Pajak Pertambahan Nilai, Pajak Terutang
}

\begin{abstract}
Weaving Company of Medali Mas is a company that doesn't have an Import Identification Number or commonly referred to as API. Since it does not have an Import Identification Number (API), it is asking for the help of another party to become an importer of material from the company. It is subject to Income Tax (PPh) Article 22 and Value Added Tax (VAT), This Company will also bear fees for importing through other parties in the current year that must be paid by the Taxpayer, namely Income Tax ( PPh). The purpose of this study was to determine how the effect of the imposition of Article 22 Income Tax and VAT based on the Taxation Law in order to determine the Debt Tax.

The data will be used in this study is primary data and secondary data. The type of data used is qualitative data and quantitative data. Data collection techniques used in this study is interviews and documentation. The variables in this study are Income Tax Article 22, VAT, tax payable. This type of research used in this research is quantitative descriptive that is by describing the results of the calculated value of the data obtained.

The results of this study indicate that if weaving companies of medali mas do import by themselves, they don't need to pay headling fees, but if they import with another party's API, the company is subject to Article 22 income tax and VAT in determining the tax payable and is still subject to headling fees. Companies use their own API, then Article 22 PPh, VAT, and Debt Tax are smaller, compared to companies using other companies' API so that Article 22, VAT and Debt Tax are greater.

Based on the discussion, weaving companies of medali mas should import using their own APIs, because if they have their own APIs, weaving companies do not need to spend funds for headling fees, Article 22 Income Tax, Value Added Tax and Debt Taxes from companies are less than using other companies' APIs.
\end{abstract}

Keywords : PPh Article 22, Value Added Tax, and Tax Due

\section{PENDAHULUAN}

Latar Belakang Masalah

Indonesia memiliki beberapa penggolongan pajak, secara garis besar pajak dikelompokkan menjadi dua, yaitu Pajak Pusat dan Pajak Daerah. Sistem pemungutannya yaitu Self Assesment System, Official Assesment System dan Witholding System. Salah satu kegiatan yang dikenakan pajak adalah impor Barang 
Kena Pajak. Impor adalah proses transportasi atau mendatangkan barang komoditas dari suatu negara ke negara lain secara legal. Impor adalah tindakan memasukkan barang atau komoditas dari negara lain ke dalam negeri. Pembayaran atas penyerahan barang dan kegiatan dibidang impor dipungut melalui Pajak Penghasilan (PPh) Pasal 22.

Pajak Penghasilan Pasal 22 impor adalah Pajak Penghasilan yang dikenakan saat dilaksankan impor barang dari luar Daerah Pabean ke dalam wilayah Pabean. Semakin banyak barang impor yang masuk ke daerah pabean maka kantor pengawasan dan pelayanan bea cukai harus semakin diperketat dalam menyeleksi barang masuk. Setiap barang yang masuk didaerah pabean harus dikenakan pajak, yaitu Pajak Penghasilan Pasal 22. Pajak Penghasilan Pasal 22, merupakan pajak dalam tahun berjalan melalui pemungutan pajak oleh bendaharawan pemerintah atau badan tertentu sehubungan dengan pembayaran atas penyerahan barang dan kegiatan dibidang impor. Pajak yang dipungut oleh pemerintah dalam rangka kegiatan impor antara lain Pajak Penghasilan Pasal 22 Impor dan Pajak Pertambahan Nilai.

Pajak Pertambahan Nilai merupakan salah satu jenis pajak tidak langsung yang termasuk sebagai pajak konsumsi didalam negeri, baik konsumsi barang maupun jasa. Pajak Pertambahan Nilai merupakan pajak yang dikenakan atas nilai tambah dari barang atau jasa setelah melalui proses produksi. Nilai tambah itu sendiri merupakan elemen utama yang digunakan sebagai dasar perhitungan Pajak Pertambahan Nilai. Pertambahan nilai itu sendiri timbul karena digunakannya faktor-faktor produksi pada setiap jalur perusahaan dalam menyiapkan, menghasilkan, menyalurkan dan memperdagangkan barang atau pemberi pelayanan jasa kepada konsumen. Pengusaha yang melakukan penyerahan barang atau jasa yang dikenakan pajak adalah Pengusaha Kena Pajak dan pengusaha tersebut wajib melaporkan usahannya, dengan kewajiban selanjutnya yang harus dilakukan oleh Wajib Pajak Badan yang bersangkutan adalah memungut, menyetorkan, melunasi dan melaporkan Pajak Penghasilan Pasal 22 dan Pajak Pertambahan Nilai yang menjadi Pajak Terutang.

Pajak Terutang adalah pajak yang harus dibayar pada suatu saat, dalam Masa Pajak, dalam Tahun Pajak, atau dalam Bagian Tahun Pajak sesuai dengan ketentuan dalam Undang-Undang Perpajakan. Kewajiban membayar Pajak Terutang berakhir saat Utang Pajak sudah dilakukan pembayaran sesuai kebiasaan umum, utang berakhir karena adanya pelunasan secara tunai atau dengan penyerahan pajak.

Penelitian ini dilakukan di Perusahaan Tenun Ikat Medali Mas yang beralamat di Jl. KH. Agus Salim Gg. 8 No. 54 C Bandar Kidul Kec. Mojoroto Kota Kediri. Perusahaan Tenun Ikat Medali Mas merupakan salah satu perusahaan yang bergerak dalam bidang kerajinan tenun ikat. Perusahaan Tenun Ikat Medali Mas Kediri menghasilkan beberapa jenis produk, seperti kain tenun, sarung goyor, dan syal. Perusahaan dalam proses produksinya menggunakan beberapa macam bahan. Bahan yang digunakan salah satunya pewarna yang digunakan untuk mewarnai benang dan benang yang digunakan dalam pembuatan tenun ikat. Perusahaan Tenun Ikat Medali Mas dalam pembuatan tenun ikat tidak menggunakan pewarna dan benang lokal, melainkan mendatangkan dari Mancanegara, yaitu Negara India dan Jepang. Perusahaan Tenun Ikat Medali Mas merupakan perusahaan yang tidak memiliki 
Angka Pengenal Impor (API). Karena tidak memiliki (API), maka impor yang di lakukan tidak secara langsung ke negara tersebut tetapi meminta bantuan pihak lain untuk menjadi pelaksanaa impor bahan dari perusahaan. Perusahaan Tenun Ikat Medali Mas selain terkena Pajak Penghasilan Pasal 22 dan Pajak Pertambahan Nilai. Perusahaan Tenun Ikat Medali Mas akan menanggung fee karena mengimpor melalui pihak lain dalam tahun berjalan yang harus di bayar oleh Wajib Pajak yaitu Pajak Penghasilan.

Berdasarkan latar belakang diatas, peneliti melakukan penelitian dengan judul "Pengaruh Pengenaan PPh Pasal 22 dan PPN Berdasarkan Undang-Undang Perpajakan Guna Menentukan Pajak Terutang."

\section{LANDASAN TEORI Pajak Penghasilan (PPh) Pasal 22}

Pajak Penghasilan Pasal 22 adalah pajak yang dipungut oleh bendaharawan baik pemerintah pusat maupun daerah, instansi atau lembaga pemerintah dan lembaga lainnya berkenaan dengan pembayaran atas penyerahan barang, dan badan tertentu baik pemerintah maupun swasta berkenaan dengan kegiatan di bidang impor atau kegiatan usaha di bidang lain.

Menurut Subadriyah (2017 : 99) menyatakan bahwa: Pajak Penghasilan (PPh) Pasal 22 adalah PPh yang dipungut oleh: Bendahara Pemerintah Pusat atau Daerah, instansi atau lembaga pemerintah dan lembaga Negara lainnya, berkenaan dengan pembayaran atas penyerahan barang, Badan-badan tertentu, baik badan pemerintah maupun swasta berkenaan dengan kegiatan di bidang impor atau kegiatan usaha lain, Wajib Pajak Badan yang melakukan penjualan barang yang tergolong sangat mewah".

\section{Pajak Pertambahan Nilai}

Menurut Sutedi (2011: 97), menyatakan bahwa:"Pajak Pertambahan Nilai adalah pajak yang dikenakan atas konsumsi Barang Kena Pajak atau Jasa Kena Pajak di Daerah Pabean. Orang Pribadi, perusahaan, pemerintah yang mengonsumsi Barang Kena Pajak atau Jasa Kena Pajak dikenakan Pajak Pertambahan Nilai ". Menurut Priantara (2016 : 419) menyatakan bahwa:"Pajak Pertambahan Nilai adalah pajak tidak langsung atas konsumsi di daerah pabean, dapat dialihkan kepada pihak lain, sepanjang pihak yang mengalihkan pajak tersebut memenuhi syarat sebagai Pengusaha Kena Pajak".

\section{Pajak Terutang}

Menurut Diana dan Setiawan (2014 : 89), menyatakan bahwa:"Pajak Terutang adalah pajak yang harus dibayar pada suatu saat, dalam Masa Pajak, dalam Tahun Pajak, atau dalam Bagian Tahun Pajak sesuai Undang-Undang Perpajakan”. Menurut Muljono (2009:47), menyatakan bahwa:"Pajak Terutang adalah besarnya Pajak Yang Terutang atas penghasilan Wajib Pajak yang dihitung pada akhir tahun”. 


\section{METODE PENELITIAN}

\section{Ruang Lingkup Penelitian}

Ruang lingkup penelitian mencangkup masalah pengenaan PPh Pasal 22 dan PPN Berdasarkan Undang-Undang Perpajakan Guna Menentukan Pajak Terutang.

\section{Identifikasi Variabel}

Variabel $1:$ PPh Pasal 22

Variabel 2 : PPN

Variabel 3 : Pajak Terutang

\section{Teknik Analisis}

Teknik analisisnya adalah deskriptif kuantitatif dengan menggunakan alat analisis sebagai berikut:

Rumus perhitungan Nilai Impor

Rumus perhitungan dari Nilai Impor (NI) adalah sebagai berikut:

$$
\mathrm{NI}=\text { Cost }+ \text { Insurance }+ \text { Freight }+ \text { Bea Masuk }
$$

Sumber: Resmi (2018 : 285)

Rumus perhitungan Pajak Penghasilan (PPh) Pasal 22 atas kegiatan impor :

a. Menggunakan Angka Pengenal Impor (API), tarif pemungutannya sebesar 2,5\% dari nilai impor.

$$
\text { PPh Pasal } 22=\text { Nilai Impor x 2,5\% }
$$

Sumber: Priantara (2016:333)

b. Tidak menggunakan Angka Pengenal Impor (API) dan meminta bantuan pihak lain untuk mengimporkan, tarif pemungutannya sebesar 2,5\% dari nilai impor ditambah fee yang sudah dipotong PPh Pasal 25

PPh Pasal 22= (Nilai Impor x 2,5\%) + Headling Fee

Sumber: Sahara (2013: 30)

Rumus perhitungan Pajak Pertambahan Nilai (PPN)

Rumus perhitungan dari Pajak Pertambahan Nilai adalah sebagai berikut:

PPN = Dasar Penggenaan Pajak x Tarif Pajak

Sumber: Priantara (2016 : 450)

Menghitung dan Menentukan Pajak Terutang 
Dalam menghitung pajak Terutang PPh Pasal 22 atas impor ada dua jenis rumus yang digunakan yang pertama Memiliki Angka Pengenal Impor (API) dan yang kedua Tidak Memiliki Angka Pengenal Impor (API) tetapi meminta bantuan pihak lain untuk mengimporkan :

a. Memiliki API

$\begin{array}{ll}\text { PPh Pasal 22 }(2,5 \% \times \mathrm{N}) & \mathrm{xxx} \\ \mathrm{PPN}(10 \% \mathrm{x} \mathrm{N}) & \underline{\mathrm{xxx}}+ \\ \text { Pajak terutang } & \mathrm{xxxx}\end{array}$

Sumber: Priantara $(2016: 333)$

b. Tidak memiliki API tetapi meminta di imporkan oleh pihak lain

PPh Pasal 22 (2,5\% x Nilai impor + Headling Fee)

XXX

PPN (10\% x Nilai impor) $\underline{\mathrm{xxx}}+$

Pajak terutang

$\mathrm{xxx}$

Sumber: Sahara $(2013: 30)$

\section{HASIL PENELITIAN DAN PEMBAHASAN}

Menghitung Nilai Impor Berdasarkan Kurs Pajak (Kurs Menteri Keuangan)

1. Perhitungan Nilai Impor Benang Katun

Tabel 1.Nilai Impor Benang Katun Periode 2020

\begin{tabular}{|l|l|c|l|}
\hline \multirow{4}{*}{} & Cost & & Rs 169.740 \\
\cline { 2 - 4 } & Insurance & $0,5 \%$ & Rs 849 \\
\cline { 2 - 4 } Januari & Freight & $5 \%$ & Rs 8.487 \\
\cline { 2 - 4 } & CIF dalam Rupee India & & Rs 179.075 \\
\cline { 2 - 4 } & $\begin{array}{l}\text { Kurs 1 Rupee = Rp 212, } \\
\text { CIF dalam Rupiah }\end{array}$ & 212 & $\operatorname{Rp~37.964.065~}$ \\
\cline { 2 - 4 } & Bea Masuk & $10 \%$ & $\operatorname{Rp~3.796.401~}$ \\
\cline { 2 - 4 } & Nilai Impor & & $\operatorname{Rp~41.760.406~}$ \\
\hline
\end{tabular}

2. Perhitungan Nilai Impor Benang Sutra

Tabel 2. Nilai Impor Benang SutraPeriode 2020

\begin{tabular}{|c|l|l|l|}
\hline \multirow{2}{*}{ Januari } & Cost & & Rs 270.508 \\
\cline { 2 - 4 } & Insurance & $0,5 \%$ & Rs 1.353 \\
\hline
\end{tabular}




\begin{tabular}{|l|l|c|l|}
\hline \multirow{2}{*}{} & Freight & $5 \%$ & Rs 13.525 \\
\cline { 2 - 4 } CIF dalam Rupee India & & Rs 285.386 \\
\cline { 2 - 4 } $\begin{array}{l}\text { Kurs 1 Rupee = Rp 212, } \\
\text { CIF dalam Rupiah }\end{array}$ & 212 & Rp 60.501.816 \\
\cline { 2 - 4 } & Bea Masuk & $10 \%$ & Rp 6.050.182 \\
\cline { 2 - 4 } & Nilai Impor & & Rp 66.551.998 \\
\hline
\end{tabular}

3. Perhitungan Nilai Impor Pewarna Tekstil

Tabel 3. Nilai Impor Pewarna Tekstil Periode 2020

\begin{tabular}{|c|l|c|l|}
\hline \multirow{5}{*}{ Januari } & Cost & & $¥ 1.607$ \\
\cline { 2 - 4 } & Insurance & $0,5 \%$ & $¥ 8$ \\
\cline { 2 - 4 } & Freight & $5 \%$ & $¥ 80$ \\
\cline { 2 - 4 } & CIF dalam Yen & & $¥ 1.696$ \\
\cline { 2 - 4 } & $\begin{array}{l}\text { Kurs 1 Yen = Rp 12.009, } \\
\text { CIF dalam Rupiah }\end{array}$ & $\mathrm{Rp} \mathrm{12.009}$ & $\mathrm{Rp} \mathrm{20.366.240}$ \\
\cline { 2 - 4 } & Bea Masuk & $10 \%$ & $\mathrm{Rp} \mathrm{2.036.624}$ \\
\hline & Nilai Impor & & $\mathrm{Rp} \mathrm{22.402.864}$ \\
\hline
\end{tabular}

\section{Menghitung Nilai Impor Berdasarkan Kurs Bank Indonesia}

1. Perhitungan Nilai Impor Benang Katun

Tabel 4. Nilai Impor Benang Katun Periode 2020

\begin{tabular}{|c|l|c|l|}
\hline \multirow{5}{*}{ Januari } & Cost & & Rs 169.740 \\
\cline { 2 - 4 } & Insurance & $0,5 \%$ & Rs 849 \\
\cline { 2 - 4 } & Freight & $5 \%$ & Rs 8.487 \\
\cline { 2 - 4 } & CIF dalam Rupee India & & Rs 179.075 \\
\cline { 2 - 4 } & $\begin{array}{l}\text { Kurs 1 Rupee = Rp 214, } \\
\text { CIF dalam Rupiah }\end{array}$ & 214 & Rp 38.322.156 \\
\cline { 2 - 4 } & Bea Masuk & $10 \%$ & Rp 3.832.216 \\
\cline { 2 - 4 } & Nilai Impor & & Rp 42.154.372 \\
\hline
\end{tabular}


2. Perhitungan Nilai Impor Benang Sutra

Tabel 5. Nilai Impor Benang Sutra Periode 2020

\begin{tabular}{|l|l|r|l|}
\hline \multirow{4}{*}{} & Cost & & Rs 270.508 \\
\cline { 2 - 4 } & Insurance & $0,5 \%$ & Rs 1.353 \\
\cline { 2 - 4 } & Freight & $5 \%$ & Rs 13.525 \\
\cline { 2 - 4 } & CIF dalam Rupee India & & Rs 285.386 \\
\cline { 2 - 4 } & $\begin{array}{l}\text { Kurs 1 Rupee = Rp 214, } \\
\text { CIF dalam Rupiah }\end{array}$ & 214 & Rp 61.072.588 \\
\cline { 2 - 4 } & Bea Masuk & $10 \%$ & Rp 6.107.259 \\
\cline { 2 - 4 } & Nilai Impor & Rp 67.179.847 \\
\cline { 2 - 4 } & & & \\
\hline
\end{tabular}

3. Perhitungan Nilai Impor Pewarna Tekstil

Tabel 6. Nilai Impor Pewarna Tekstil Periode 2020

\begin{tabular}{|l|l|c|l|}
\hline \multirow{7}{*}{} & Cost & & $¥ 1.607$ \\
\cline { 2 - 4 } Januari & Insurance & $0,5 \%$ & $¥ 8$ \\
\cline { 2 - 4 } & Freight & $5 \%$ & $¥ 80$ \\
\cline { 2 - 4 } & CIF dalam Yen & & $¥ 1.696$ \\
\cline { 2 - 4 } & $\begin{array}{l}\text { Kurs 1 Yen = Rp 12.317, } \\
\text { CIF dalam Rupiah }\end{array}$ & $\mathrm{Rp} \mathrm{12.317}$ & $\mathrm{Rp} \mathrm{20.888.008}$ \\
\cline { 2 - 4 } & Bea Masuk & $10 \%$ & $\mathrm{Rp} \mathrm{2088.801}$ \\
\cline { 2 - 4 } & Nilai Impor & $\mathrm{Rp} \mathrm{22.976.809}$ \\
\hline
\end{tabular}

\section{Menghitung PPh Pasal 22 atas Kegiatan Impor dengan API Sendiri}

1. Menghitung PPh Pasal 22 atas Pembelian Benang Katun

Tabel 7. PPh Pasal 22 atas Impor Benang Katun Periode 2020

\begin{tabular}{|l|cl|l|ll|}
\hline Bulan & \multicolumn{2}{|l|}{ Nilai Impor } & Tarif & \multicolumn{2}{l|}{ Jumlah } \\
\hline Januari & $\mathrm{Rp}$ & 41.760 .406 & $2,50 \%$ & $\mathrm{Rp}$ & 1.044 .010 \\
\hline Februari & $\mathrm{Rp}$ & 68.193 .462 & $2,50 \%$ & $\mathrm{Rp}$ & 1.704 .837 \\
\hline Maret & $\mathrm{Rp}$ & 56.042 .423 & $2,50 \%$ & $\mathrm{Rp}$ & 1.401 .061 \\
\hline
\end{tabular}


2. Menghitung PPh Pasal 22 atas Pembelian Benang Sutra

Tabel 8. PPh Pasal 22 atas Impor Benang Sutra Periode 2020

\begin{tabular}{|l|cc|l|ll|}
\hline Bulan & \multicolumn{2}{|l|}{ Nilai Impor } & Tarif & \multicolumn{2}{|l|}{ Jumlah } \\
\hline Januari & $\mathrm{Rp}$ & 66.551 .998 & $2,50 \%$ & $\mathrm{Rp}$ & 1.663 .800 \\
\hline Februari & $\mathrm{Rp}$ & 51.068 .303 & $2,50 \%$ & $\mathrm{Rp}$ & 1.276 .708 \\
\hline Maret & $\mathrm{Rp}$ & 66.412 .025 & $2,50 \%$ & $\mathrm{Rp}$ & 1.660 .301 \\
\hline
\end{tabular}

3. Menghitung PPh Pasal 22 atas Pewarna Tekstil

Tabel 9. PPh Pasal 22 atas Impor Pewarna Tekstil Periode 2020

\begin{tabular}{|l|l|l|l|}
\hline Bulan & Nilai Impor & Tarif & Jumlah \\
\hline Januari & Rp 22.402.864 & $2,50 \%$ & $\operatorname{Rp~560.072~}$ \\
\hline Februari & Rp 30.247.230 & $2,50 \%$ & Rp 756.181 \\
\hline Maret & Rp 23.476.240 & $2,50 \%$ & Rp 586.906 \\
\hline
\end{tabular}

\section{Menghitung PPh Pasal 22 atas Kegiatan Impor dengan API Pihak Lain}

1. Menghitung PPh Pasal 22 Impor dengan API Pihak Lain atas Pembelian Benang Katun

Tabel 10. PPh Pasal 22 Impor Benang Katun dengan API Pihak Lain Periode 2020

\begin{tabular}{|c|c|c|c|c|}
\hline Bulan & Nilai Impor & $\begin{array}{l}\text { PPh Pasal } 22 \\
(\text { N.I x 2,5\%) }\end{array}$ & $\begin{array}{c}\text { Headling } \\
\text { Fee } \\
\text { (N.I x } \\
1,5 \%)\end{array}$ & $\begin{array}{c}\text { Jumlah yang } \\
\text { Dibayarkan }\end{array}$ \\
\hline Januari & $\begin{array}{l}\mathrm{Rp} \\
42.154 .372\end{array}$ & Rp 1.053.859 & $\operatorname{Rp} 632.316$ & Rp 43.840.547 \\
\hline Februari & $\begin{array}{l}\mathrm{Rp} \\
68.846 .031\end{array}$ & Rp 1.721.151 & $\begin{array}{l}\mathrm{Rp} \\
1.032 .690\end{array}$ & $\mathrm{Rp} 71.599 .872$ \\
\hline Maret & $\begin{array}{l}\mathrm{Rp} \\
56.839 .234\end{array}$ & Rp 1.420.981 & Rp 852.589 & Rp 59.112.803 \\
\hline
\end{tabular}

2. Menghitung PPh Pasal 22 Impor dengan API Pihak Lain atas Pembelian Benang

Sutra

Table 11. PPh Pasal 22 Impor Benang Sutra dengan API Pihak Lain Periode 2020

\begin{tabular}{|c|c|c|c|c|}
\hline Bulan & Nilai Impor & $\begin{array}{c}\text { PPh Pasal } \\
22 \\
(\mathrm{~N} . \mathrm{I} x \\
2,5 \%)\end{array}$ & $\begin{array}{l}\text { Headling Fee } \\
\text { (N.I x 1,5\%) }\end{array}$ & $\begin{array}{c}\text { Jumlah yang } \\
\text { Dibayarkan }\end{array}$ \\
\hline Januari & Rp 67.179.847 & $\begin{array}{l}\mathrm{Rp} \\
1.679 .496\end{array}$ & Rp 1.007.698 & Rp 69.867.041 \\
\hline Februari & $\operatorname{Rp} 51.556 .995$ & $\mathrm{Rp}$ & Rp 773.355 & Rp 53.619.275 \\
\hline
\end{tabular}




\begin{tabular}{|l|l|l|l|l|} 
& & 1.288 .925 & & \\
\hline & & $\operatorname{Rp}$ & & \\
Maret & $\operatorname{Rp~67.356.272~}$ & 1.683 .907 & $\operatorname{Rp~1.010.344~}$ & $\operatorname{Rp~70.050.523~}$ \\
\hline
\end{tabular}

3. Menghitung PPh Pasal 22 Impor dengan API Pihak Lain atas Pembelian Pewarna Tekstil

Tabel 12. PPh Pasal 22 Impor Pewarna dengan API Pihak Lain Periode 2020

\begin{tabular}{|c|c|c|c|c|}
\hline Bulan & Nilai Impor & $\begin{array}{l}\text { PPh Pasal } 22 \\
(\text { N.I x } 2,5 \%)\end{array}$ & $\begin{array}{l}\text { Headling Fee } \\
\text { (N.I x } 1,5 \%)\end{array}$ & $\begin{array}{c}\text { Jumlah yang } \\
\text { Dibayarkan }\end{array}$ \\
\hline Januari & Rp 22.976.809 & $\operatorname{Rp} 574.420$ & $\operatorname{Rp} 344.652$ & Rp 23.895.881 \\
\hline Februari & Rp 31.756.059 & Rp 793.901 & Rp 476.341 & Rp 33.026.301 \\
\hline Maret & $\operatorname{Rp} 23.769 .817$ & Rp 594.245 & Rp 356.547 & $\operatorname{Rp} 24.720 .610$ \\
\hline
\end{tabular}

Menghitung PPN Menggunakan API Sendiri dan Kurs Pajak (Kurs Menteri Keuangan)

. 1. Menghitung PPN Benang Katun

Tabel 13. PPN Benang Katun Periode 2020

\begin{tabular}{|l|l|l|ll|}
\hline Bulan & DPP & Tarif & \multicolumn{2}{l|}{ Jumlah } \\
\hline Januari & $\operatorname{Rp~} 41.760 .406$ & $10,00 \%$ & $\operatorname{Rp} 4.176 .041$ \\
\hline Februari & $\operatorname{Rp} 68.193 .462$ & $10,00 \%$ & $\operatorname{Rp} 6.819 .346$ \\
\hline Maret & $\operatorname{Rp} 56.042 .423$ & $10,00 \%$ & $\operatorname{Rp} 5.604 .242$ \\
\hline
\end{tabular}

2. Menghitung PPN Benang Sutra

Tabel 14. PPN Benang Sutra Periode 2020

\begin{tabular}{|c|c|c|c|}
\hline Bulan & DPP & Tarif & Jumlah \\
\hline Januari & Rp $\quad 66.551 .998$ & $10,00 \%$ & $\begin{array}{ll}\text { Rp } & 6.655 .200 \\
\end{array}$ \\
\hline Februari & Rp 51.068 .303 & $10,00 \%$ & Rp 5.106 .830 \\
\hline Maret & Rp $\quad 66.412 .025$ & $10,00 \%$ & 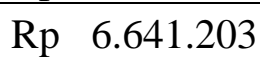 \\
\hline
\end{tabular}

3. Menghitung PPN Pewarna Tekstil

Tabel 15. PPN Pewarna Tekstil Periode 2020

\begin{tabular}{|l|l|l|l|}
\hline Bulan & DPP & Tarif & Jumlah \\
\hline Januari & Rp 22.402.864 & $10,00 \%$ & Rp 2.240.286 \\
\hline Februari & Rp 30.247.230 & $10,00 \%$ & $\operatorname{Rp~3.024.723~}$ \\
\hline Maret & Rp 23.476.240 & $10,00 \%$ & $\operatorname{Rp~2.347.624~}$ \\
\hline
\end{tabular}

4. Menghitung PPN Benang Katun

Tabel 16. PPN Benang Katun Periode 2020

\begin{tabular}{|l|l|l|l|}
\hline Bulan & DPP & Tarif & Jumlah \\
\hline Januari & $\operatorname{Rp} 42.154 .372$ & $10,00 \%$ & $\operatorname{Rp~4.215.437~}$ \\
\hline
\end{tabular}




\begin{tabular}{|l|l|l|l|} 
Februari & $\operatorname{Rp} 68.846 .031$ & $10,00 \%$ & $\operatorname{Rp} 6.884 .603$ \\
\hline Maret & Rp 56.839.234 & $10,00 \%$ & Rp 5.683.923 \\
\hline
\end{tabular}

5. Menghitung PPN Benang Sutra

Tabel 17. PPN Benang Sutra Periode 2020

6. Menghitung PPN Pewarna Tekstil

\begin{tabular}{|l|l|l|l|}
\hline Bulan & DPP & Tarif & Jumlah \\
\hline Januari & $\operatorname{Rp~} 67.179 .847$ & $10,00 \%$ & $\operatorname{Rp} 6.717 .985$ \\
\hline Februari & $\operatorname{Rp~51.556.995~}$ & $10,00 \%$ & $\operatorname{Rp~5.155.700~}$ \\
\hline Maret & $\operatorname{Rp} 67.356 .272$ & $10,00 \%$ & $\operatorname{Rp} 6.735 .627$ \\
\hline
\end{tabular}

Tabel 18. PPN Pewarna Tekstil Periode 2020

\begin{tabular}{|l|l|l|l|}
\hline Bulan & DPP & Tarif & Jumlah \\
\hline Januari & $\operatorname{Rp} 22.976 .809$ & $10,00 \%$ & $\operatorname{Rp} 2.297 .681$ \\
\hline Februari & $\operatorname{Rp} 31.756 .059$ & $10,00 \%$ & $\operatorname{Rp} 3.175 .606$ \\
\hline Maret & $\operatorname{Rp} 23.769 .817$ & $10,00 \%$ & $\operatorname{Rp} 2.376 .982$ \\
\hline
\end{tabular}

Menghitung dan Menentukan Pajak Terutang

1. Menghitung dan Menentukan Pajak Terutang dengan Memiliki API

Tabel 19. Pajak Terutang dengan API Sendiri Periode 2020

\begin{tabular}{|l|l|l|l|}
\hline \multicolumn{1}{|c|}{ Bulan } & \multicolumn{1}{|c|}{ PPh Pasal 22 } & \multicolumn{1}{c|}{ PPN } & \multicolumn{1}{c|}{ Pajak Terutang } \\
\hline Januari & Rp 3.267.882 & Rp 13.071.527 & Rp 16.339.408 \\
\hline Februari & Rp 3.737.725 & Rp 14.950.900 & Rp 18.688.624 \\
\hline Maret & Rp 3.648.267 & Rp 14.593.069 & Rp 18.241.336 \\
\hline
\end{tabular}

2. Menghitung dan Menentukan Pajak Terutang dengan API Pihak Lain

Tabel 20. Pajak Terutang dengan API Pihak Lain Periode 2020

\begin{tabular}{|l|l|l|l|}
\hline \multicolumn{1}{|c|}{ Bulan } & \multicolumn{1}{|c|}{ PPh Pasal 22 } & \multicolumn{1}{c|}{ PPN } & Pajak Terutang \\
\hline Januari & Rp 3.307.776 & Rp 13.231.103 & Rp 16.538.879 \\
\hline Februari & Rp 3.803.977 & Rp 15.215.909 & Rp 19.019.886 \\
\hline Maret & Rp 3.699.133 & Rp 14.796.532 & Rp 18.495.665 \\
\hline
\end{tabular}




\section{KESIMPULAN DAN SARAN \\ Kesimpulan}

Berdasarkan hasil penelitian dan pembahasan yang telah dilakukan pada Perusahaan Tenun Ikat Medali Mas maka dapat ditarik kesimpulan sebagai berikut:

1. Perusahaan Tenun Ikat Medali Mas belum memiliki API, sehingga menggunakan API pihak lain untuk pembelian bahan baku yang berasal dari negara lain.

2. PPh Pasal 22 impor menggunakan API sendiri dengan kurs Pajak sebesar Rp 44.658.313 dan PPh Pasal 22 impor menggunakan API pihak lain dengan kurs Bank Indonesia sebesar Rp 45.245.392.

3. Pajak Pertambahan Nilai impor menggunakan API sendiri dengan kurs Pajak sebesar Rp 178.633.254 dan Pajak Pertambahan Nilai impor menggunakan API pihak lain dengan kurs Bank Indonesia sebesar Rp 180.981.568.

4. Pajak Terutang yang akan dibayarkan jika menggunakan API sendiri lebih kecil dibandingkan menggunakan API pihak lain. Perusahaan jika menggunakan API pihak lain harus membayar headling fee sebesar Rp 27.147.235 kepada pemilik API.

\section{Saran}

Saran peneliti adalah sebagai berikut:

1. Bagi Perusahaan Tenun Ikat Medali Mas

Perusahaan sebaiknya memiliki API sendiri, karena jika memiliki API sendiri, Perusahaan Tenun Ikat Medali Mas tidak perlu mengeluarkan dana untuk headling fee, PPh Pasal 22, Pajak Pertambahan Nilai, dan Pajak Terutang dari perusahaan lebih sedikit daripada menggunakan API perusahaan lain.

2. Bagi Peneliti Selanjutnya

Penelitian selanjutnya dapat mengkaji lebih dalam pada cakupan yang lebih luas atau pada perusahaan lain, sehingga hasil penelitian selanjutnya diharapkan mampu memberikan kontribusi yang lebih berarti dalam meningkatkan pemahaman tentang perpajakan

\section{Daftar Pustaka}

Fitriandi, Primandita, Yuda Aryanto dan Agus Puji Priyono. 2015. Kompilasi Undang-Undang Perpajakan, Edisi 1. Jakarta: Salemba Empat.

IKPI. 2019. Panduan Brevet Pajak. Cabang Malang.

Kemenkeu. 2018. Peraturan Menteri Keuangan 16/PMK.010/2016. https://jdih.kemenkeu.go.id/fulltext/2016/16 PMK.010 2016Per.pdf Diakses tanggal 18 Desember 2018 Pukul 23:44

Mardiasmo. 2016. Perpajakan Edisi Terbaru. Yogyakarta: Andi.

Muljono, Djoko. 2010. Panduan Brevet Pajak - Pajak Penghasilan, Edisi 1. Yogyakarta: ANDI.

Priantara, Diaz. 2016. Perpajakan Indonesia, Edisi 3. Jakarta: Mitra Wacana Media.

Resmi, Siti. 2017. Perpajakan - Teori dan Kasus, Edisi 10. Jakarta: Salemba Empat. 
Jurnal Cendekia ARuntansi Vol. 2 No.1

Sahara, Khasanah. 2013. Buku Ajar - Perpajakan untuk Prodi Akuntansi. Perpustakaan Uniska.

Subadriyah. 2017. Pajak Penghasilan, Edisi 1. Yogyakarta: Pustaka Pelajar.

Sutedi, Adrian. 2011. Hukum Pajak, Edisi 1. Jakarta: Sinar Grafika. 